\title{
ATIVIDADES EXPERIMENTAIS INVESTIGATIVAS NA DISCIPLINA DE QUÍMICA: PERSPECTIVAS E POSSIBILIDADES
}

\author{
Débora Cristina Curto da Costa Bocato \\ Universidade Estadual de Maringá. Programa de Educação para a Ciência e a Matemática, Maringá-PR. E-mail: \\ deboracurto@hotmail.com
}

\section{RESUMO}

O objetivo foi apontar os possíveis benefícios das atividades experimentais investigativas frente a aprendizagem dos conceitos químicos numa (re)construção do saber. Para tanto, foi utilizada a pesquisa bibliográfica exploratória com a visão de alguns estudiosos como Chassot, Maldaner, Mortimer, Hodson, Gil-Pérez e Valdez Castro, Gonzales, dentre outros, sobre a aplicação de atividades experimentais na disciplina de química. Almeja-se, com o presente trabalho, demonstrar que as atividades experimentais, quando realizadas dentro de uma proposta investigativa com foco na problematização dos conteúdos, podem funcionar como mecanismo de motivação para o estudo, facilitando a aprendizagem dos conceitos e possibilitando a superação de alguns obstáculos pedagógicos.

Palavras - chave: Atividades experimentais. Investigação. Aprendizagem de Química.

\section{EXPERIMENTAL INVESTIGATIVE ACTIVITIES IN CHEMISTRY DISCIPLINE: PROSPECTS AND POSSIBILITIES}

\begin{abstract}
The objective was point the potential benefits of the experimental investigative activities against learning of chemical concepts in a (re)construction of knowledge. Therefore, the bibliographical research was used with the view of some scholars as Chassot, Maldaner, Mortimer, Hodson, Gilperez and Valdez Castro, Gonzales, among others, on the application of experimental activities in the chemistry discipline. The present study aims to demonstrate that the experimental activities, when performed within a research proposal focused on questioning the content, this can act as motivation mechanism for the study, facilitating the learning of concepts and enabling overcome some educational obstacles.
\end{abstract}

keywords: Experimental Activities. Research. Chemistry Learning. 


\section{INTRODUÇÃO}

Ainda nos dias atuais, frente a uma sociedade em constante transformação científica e tecnológica, constata-se que as escolas não estão conseguindo acompanhar as novas exigências da sociedade moderna, resultando em um notório fracasso escolar, que se traduz na falta de interesse e, até mesmo, na recusa por parte dos alunos ao estudo de ciências. Verifica-se a necessidade de uma proposta de (re)orientação da educação científica por meio de novas abordagens da ciência no contexto de ensino e aprendizagem, que procurem ir além da mera transmissão de conhecimentos científicos e que se apoiem na (re)construção do saber.

Pesquisas sobre metodologias de ensino, didática, formação e capacitação de professores na área de ciências têm se intensificado nas últimas décadas. A demanda pelo desenvolvimento de atividades pedagógicas nas escolas com o intuito de motivar e despertar o interesse dos educandos para o estudo das ciências aumenta a cada dia. Muitos estudiosos e profissionais do ensino têm discutido e indicado inúmeros fatores que dificultam a melhoria da prática educativa na disciplina de Química. Alguns pesquisadores têm sugerido uma abordagem investigativa dos conteúdos químicos propondo o ensino numa relação dialógica, na qual o professor atue planejando, dirigindo e organizando o processo de ensino aprendizagem e o aluno opere como participante ativo e interativo na construção do seu conhecimento (MORTIMER, 1992; CARVALHO et al; GIL PERES et al)

A educação científica é uma emergência na sociedade atual, pois constantemente o ser humano se depara com situações que exigem o conhecimento de informação científica para realizar opções ou mesmo para participar de discussões públicas sobre assuntos importantes ligados à ciência e à tecnologia, além da necessária compreensão do mundo natural para sua promoção e realização pessoal. A alfabetização científica pode proporcionar aos indivíduos condições de atuar, participar e discutir, de forma fundamentada, de questões sócio-científicas-tecnológicas, podendo aplicar os conhecimentos científicos adquiridos em sua vida diária (CACHAPUZ, 2011). Para atingir tal objetivo, torna-se relevante que o professor demonstre o longo caminho percorrido para o crescimento do conhecimento, levando o aluno a compreender o dinamismo e as dificuldades enfrentadas pela ciência desde os primórdios até os dias atuais, mostrando que as teorias atualmente aceitas são resultados de 
intensas discussões e contradições ao longo do tempo.

O fato é que ainda hoje, o que ainda predomina no âmbito escolar é o desenvolvimento de práticas pedagógicas alicerçadas em ideias empiristas, no qual o experimento segue procedimentos rigorosos, como se fossem receitas infalíveis (CACHAPUZ, 2011). Não são oferecidas aos alunos muitas possibilidades de participação ativa na coleta de dados, elaboração de hipótese e busca por respostas. Os experimentos são apresentados pelo professor, detentor do conhecimento, por meio de um roteiro rígido, colocando a ciência como algo absoluto, imutável e inquestionável. Cabe aos iniciantes observar rigorosamente o experimento e anotar tudo o que puder de modo a inferir hipóteses e modelos a partir de tais anotações. Desta forma, apenas executam a atividade proposta de forma passiva, seguindo e aceitando todos os protocolos já estabelecidos, buscando ao máximo se aproximar dos resultados esperados (LIMA et al., 2000).

No entanto, a concepção construtivista defendida nas últimas décadas tem como ponto central a participação ativa do aluno no processo de construção do conhecimento e o professor como mediador/facilitador da aprendizagem, propondo aos estudantes situações problemáticas que induzam a busca por soluções satisfatórias, por meio de levantamento de hipóteses, argumentações, dúvidas e discussões com os colegas e com o professor sobre os fenômenos estudados. Acrdita-se que a experimentação quando desenvolvida dentro do método investigativo por meio de questões problematizadoras e questionadoras favorece o desenvolvimento de habilidades cognitivas e consequentemente a compreensão dos conceitos químicos (CARVALHO et al. (ano?); GIL PERES et al. ano?)

O uso de aulas práticas nas aulas de química como ferramenta facilitadora da aprendizagem, vem sendo amplamente discutido por vários estudiosos. Os quais criticam o desenvolvimento de atividades experimentais voltadas para a simples execução de roteiros pré-estabelecidos, de modo totalmente empírico e descontextualizado (HODSON, 1994; GILPÉREZ; VALDES CASTRO (1996); GONZALES (1992).

Pretende-se demonstrar os possíveis benefícios das atividades experimentais quando desenvolvidas dentro de pressupostos epistemologicamente construtivistas com foco na participação ativa e interativa em todo o processo investigativo. Conduzindo o aprendiz a pesquisa, investigação, questionamentos, reflexões e 
busca por respostas satisfatórias às questões apresentadas.

\section{FUNDAMENTAÇÃO TEÓRICA}

Considerando a relevância do estudo das ciências na atualidade, constata-se a pertinência dos conhecimentos científicos escolares para a formação de cidadãos conscientes e autônomos com uma visão mais elaborada e sistematizada sobre os fenômenos que os cercam.

Mesmo frente às novas tendências pedagógicas, vários professores insistem em utilizar o método tradicional de ensino. 0 qual pode ser entendido a partir da transmissão dos conteúdos pelo professor, onde $\mathrm{o}$ aluno se comporta, de forma passiva, como mero receptor. Assim, as informações são repassadas sem sofrerem transformações ou adaptações, prejudicando o processo de ensino-aprendizagem. Neste cenário o aluno não consegue entender os conteúdos por não encontrar sentido nos mesmos, ou seja, não consegue relacionar o que é transmitido com a sua pratica social.

No ensino de química o aluno é muitas vezes induzido a utilizar apenas as fórmulas matemáticas para chegar aos resultados, entretanto não é indagado a relacionar o que estudou na aula de química com o seu cotidiano. Na verdade esse aluno não apreendeu um conceito, não o compreendeu em sua essência, apenas memorizou sua fórmula.

Fato semelhante ocorre nas atividades experimentais, onde muitas vezes, os alunos são convidados a realizarem aulas práticas simplesmente para fazerem experiências, as quais se revelam desconectadas da sua prática social e, até mesmo, dos conteúdos relacionados à disciplina de Química (CHASSOT, 1990). Cabe aos iniciantes observar rigorosamente o experimento e anotar tudo o que puder de modo a inferir hipóteses e modelos a partir de tais anotações. Desta forma, apenas executam a atividade proposta de forma passiva, seguindo e aceitando todos os protocolos já estabelecidos, buscando ao máximo se aproximar dos resultados esperados (LIMA et al., 2000). Ao final da atividade, nota-se que o aluno não conseguiu compreender os conteúdos que embasam o experimento; apenas observou, de forma passiva, os fenômenos, sem uma efetiva reflexão que pudesse despertar seu interesse por novas descobertas.

Isso ocorre porque estudantes, professores e a maioria da sociedade acreditam que a ciência funciona dentro de um caminho pré-determinado, guiado por um "método científico rigoroso", o qual conduz a formulação de teorias que se sucedem espontânea e naturalmente, pela 
sua maior validade e lógica, sem que haja contestações na produção do conhecimento.

Estudos e questionamentos, abrangendo o funcionamento e métodos da ciência apresentam raízes no século XVII, oriundos da epistemologia de Francis Bacon, que estabeleceu o método empiristaindutivista. Para Bacon (1979), a ciência baseia-se exclusivamente na observação neutra, na experimentação e na indução, e não em especulações teóricas, criatividade ou preconcepções sobre o objeto de estudo. Segundo o filósofo, a falta de neutralidade durante a coleta e análise dos dados "fornecidos" pela Natureza, bem como a influência de ideias prévias, oriundas de situações e experiências anteriores, podem distorcer a visão sobre a realidade e a interpretação do mundo.

Tal concepção ingênua afirma que a ciência é um conhecimento que formula e comprova leis e teorias a partir de observações dos fenômenos naturais de forma totalmente neutra, acrítica e ahistórica. Porém, não existe observação totalmente neutra, qualquer observação está sempre ligada à interpretação, sendo portanto, indissociáveis. O método acima, conhecido como empírico-indutivista, coloca a atividade científica como verdade absoluta e inquestionável, sendo que as teorias resultantes de métodos rigorosos de pesquisas, cientificamente comprovados e infalíveis.

A epistemologia de Francis Bacon realizou uma avaliação prescritiva de desenvolvimento científico que, por meio de um método rigoroso, realizado em etapas fixas, firmes e bem definidas, permitia alcançar o conhecimento verdadeiro. Contudo, sabe-se que a ciência não funciona desta forma linear e imparcial, uma vez que, por exemplo, antes mesmo de ir ao laboratório o pesquisador já sabe a priori o que vai pesquisar, dispondo de uma teoria antes da observação, de modo que sua análise jamais é neutra (SANTIN FILHO, 2011). Em suma, sempre que houver uma observação ela será sempre relacionada com algum conhecimento prévio.

O uso de tal método nas atividades experimentais, sem reflexões, com caráter totalmente acrítico e a-histórico, conduz a disseminação de uma concepção ingênua e equivocada da ciência, a qual não leva em consideração a natureza dos conhecimentos científicos e a trajetória percorrida pela ciência, contradizendo com as ideias de filósofos atuais de que o conhecimento é algo aberto, sujeito a alterações e transformações ao longo do tempo.

Por isso é preciso se ater aos perigos do reducionismo, do fazer pelo fazer, nas atividades experimentais. Muitas vezes, os alunos participam de aulas práticas 
simplesmente para fazerem experiências, as quais se revelam desconexas da sua prática social e, até mesmo, dos conteúdos relacionados à disciplina de Química (CHASSOT, 1990), abordados de modo exclusivamente não-social e anacrônico.

Outra situação que merece atenção refere-se às demonstrações experimentais executadas pelos professores, nas quais os alunos não têm participação ativa. Sendo desenvolvidas por meio de metodologias de ensino inadequadas, desvalorizando o caráter investigativo do procedimento (LIMA et al., 2000; GIL PÉREZ; VALDÉS, 1996). Tal atitude não desperta duvidas e inquietações nos alunos e os impede de adquirir novos e superiores conhecimentos.

Diferentemente do que expressa o senso comum, a ciência não resulta na verdade absoluta. A ciência apresenta um caráter processual e por isso não é algo pronto e acabado, mas se caracteriza por um processo de investigação constante e contínuo carregado de intenções e escolhas, incertezas e certezas temporárias que dão sentido a compreensão das coisas e da própria vida. (REIS-TOZZONI, ano?? ). A ciência é construída pelo ser humano e, por isso, susceptível a erros e não é um resultado final, mas um processo em constante transformação, daí o caráter transitório das teorias e a não permanência das soluções
(LAUDAN, 2011). Constata-se, desse modo, que, ao longo do tempo, os critérios para a solução de um problema evoluem e aquilo que era visto como solução adequada em determinado período em outro deixou de ser. Então, novas questões surgem, sendo necessária a formulação de novas e superiores explicações.

A ciência é complexa e diacrônica, pois se encontra em constantes mudanças e transformações, visando atender a resolução de problemas oriundos de cada época e em situações distintas (LAUDAN, 2011). Daí a necessidade de contextualização da disciplina de Química pelo professor, contemplando sua história e apresentando as teorias como algo transitório e jamais definitivo, ou seja, as teorias são aceitas, modificadas ou, até mesmo, descartadas, conforme as necessidades de cada contexto. É de extrema importância que os alunos consigam superar a visão simplista que possuem sobre ciência como verdade absoluta, imutável e inquestionável, para uma compreensão da ciência como algo em constante transformação.

Por isso, a atividade experimental necessita ser apresentadas sob a forma de investigação no processo de ensinoaprendizagem e não apenas ilustrar a teoria como verdade absoluta e inquestionável. Deve se mostrar como ponto de partida para que os alunos (re)construam explicações 
acerca dos fenômenos ocorridos durante o experimento. Então, para se atingir a aprendizagem efetiva dos conceitos químicos, utilizando as atividades experimentais como ferramenta auxiliar é preciso ir além da simples observação de fatos e anotações criteriosas, pois existem aspectos relevantes que devem ser problematizados e investigados. Além disso, a simples observações pode conduzir a reflexões incorretas e inconsistentes. Portanto, desenvolver uma aula seguindo um método rigoroso de anotações e observações neutras reforçam uma visão ingênua $e$ distorcida da ciência e seus métodos e acaba transferindo concepções equivocadas da atividade científica aos alunos.

Um dos principais objetivos do professor é fazer com que os alunos consigam interpretar transformações químicas, procurando através de suas aulas transmitir ou transferir seus próprios conceitos por meio de aulas expositivas e repetição de exercícios (MALDANER, 1995; PIEDADE, 1995). Constata-se, ainda, que, em muitos casos, o ensino de Química tem se resumido a cálculos matemáticos, à memorização de fórmulas e nomenclaturas, ocorrendo desvalorização dos aspectos conceituais e o consequente esvaziamento de conteúdos.

Por isso, é preciso que o professor tenha clareza acerca de suas concepções epistemológicas, a fim de refletir sobre sua prática e buscar os direcionamentos necessários para uma didática consciente e planejada, a qual possa trazer benefícios a aprendizagem dos alunos. Considerando que, toda metodologia encontra-se impregnada de valores e concepções, mesmo que o professor não perceba.

A transmissão dos conteúdos, dos conhecimentos científicos, as habilidades, atitudes, etc., não pode ocorrer de forma mecânica, do professor para o aluno, sem que este esteja motivado. A aprendizagem efetiva só ocorre quando, pela intervenção do professor e o uso de atividades estimulantes, as atividades físicas e mentais são mobilizadas para o estudo da matéria (LIBÂNEO, 1995). Tal processo é denominado de assimilação ativa, no sentido de que é o próprio aluno, pela sua atividade, sua participação que se ajusta aos conhecimentos e de tudo mais que se disponibilize no processo educativo.

Sendo o conhecimento resultados de intensas interações entre o sujeito e o contexto social no qual está inserido, existem diferentes formas de pensar, agir e, consequentemente, de aprender e, por isso, cada aluno apresenta características peculiares. Assim, é preciso compreender qual o perfil de cada aluno e, com isso, constatar quais obstáculos necessitam ser superados para a efetiva aprendizagem. 
Elaborando, assim propostas pedagógicas de ensino adequadas à realidade de cada educando.

O fato é que muitos professores não têm noção da existência dos obstáculos epistemológicos em seus alunos e não entendem por que tais alunos não compreendem conceitos já adquiridos. $\mathrm{Na}$ verdade, o obstáculo se encontra impregnado no conhecimento não questionado. Existem educadores que acreditam poder reconstruir conceitos falhos através da repetição de uma determinada lição (BACHELARD, 1996). Entretanto, o aluno não consegue encontrar significado no que Ihe é transmitido porque não é indagado a levantar questionamentos e refletir sobre o conteúdo apresentado, apenas o incorpora, sem compreendê-lo em sua essência, resultando posteriormente em obstáculos para a aprendizagem.

Ainda, segundo Bachelard (1996), para o aprendizado de um novo saber, é preciso ir contra um conhecimento anterior, destruindo conceitos mal estabelecidos para dar lugar a conhecimentos superiores. Porém, o abandono de um conhecimento prévio nem sempre é uma tarefa fácil, pois, muitas vezes, ocorre a resistência por parte do aprendiz, remetendo a dificuldades de superação do obstáculo e, por consequência, dificuldades no aprendizado.
O aprendizado do conhecimento elaborado requer negação do passado, de crenças e valores antigos em prol do pensamento abstrato, mediante reflexões profundas e indagações. Tais fatores remetem à busca por respostas que requerem resoluções satisfatórias que, em muitos casos, são de difícil compreensão (BACHELARD, 1996). Daí a necessidade de desenvolver estratégias de ensino inovadoras, as quais conduzam a inquietações e reflexões, de modo que o aluno possa perceber que suas concepções prévias não estão conseguindo responder de forma adequada as questões apresentadas, motivando-o a buscar por novos e superiores conhecimentos.

Os procedimentos experimentais necessitam sempre de uma explicação científica baseada em seus pressupostos teóricos. Quando utilizados como receita, não colaboram para a superação dos obstáculos e consequente aquisição de novos conceitos (LIMA et al., 2000). Isto porque os alunos não encontram significado nos experimentos e, portanto, não são capazes de identificar os conceitos e fenômenos envolvidos no processo. Nessa perspectiva, a atividade prática empregada apenas como ilustração, verificação e observação, seguindo roteiros rigorosos, como se fossem receitas infalíveis sem explorar o caráter 
investigativo do experimento, não contribui para o aprendizado de novos conhecimentos.

Neste seguimento os PCNEM corroboram da seguinte forma:

O aspecto formativo das atividades práticas experimentais não pode ser negligenciado a um caráter superficial, mecânico e repetitivo, em detrimento da promoção de aprendizados efetivamente articuladores do diálogo entre saberes teóricos e práticos dinâmicos, processuais e relevantes para os sujeitos em formação. Ou seja, é essencial que as atividades práticas, em vez de se restringirem aos procedimentos experimentais, permitam ricos momentos de estudo e discussão teórico/prática que, transcendendo os conhecimentos de nível fenomenológico e os saberes expressos pelos alunos, ajudem na compreensão teóricoconceitual da situação real, mediante $\mathrm{o}$ uso de linguagens e modelos explicativos específicos que, incapazes de serem produzidos de forma direta, dependem de interações fecundas na problematização e na (re)significação conceitual pela intervenção do professor (BRASIL, 2006).

A experimentação é uma ferramenta necessária para facilitar a aprendizagem dos conceitos. Porém, vale ressaltar que, em muitas situações, é mal utilizada pelos professores (MALDANER, 2003; CHASSOT, 2004). Não basta apenas que o professor realize atividades experimentais. É preciso que ele saiba conduzi-las, de modo a oferecer benefícios na compreensão dos fenômenos químicos estudados.

Outro aspecto relevante a ser destacado é o ensino da Química para a formação de cidadãos mais conscientes e críticos. O estudo da Química deve possibilitar ao ser humano uma visão mais crítica do mundo que o cerca, propiciandoIhe a capacidade de analisar, compreender, dar sugestões e utilizar esses conhecimentos em sua vida (CHASSOT, 1990). A Química é também uma linguagem; assim, o ensino desse componente curricular deve ser um facilitador da leitura do mundo. Ensina-se Química para permitir que o cidadão possa interagir melhor com o mundo.

Estudos revelam que, muitas vezes, as atividades investigativas funcionam como mecanismo de motivação. Portanto, tais atividades necessitam do engajamento de conceitos científicos e não devem se limitar ao exercício empirista. Desse modo, deve-se tomar o cuidado de não fazer um experimento pelo experimento, ou seja, desvinculado do que está sendo estudado (CHASSOT, 2004; MALDANER, 1995). Então as aulas práticas de química não podem estar 
desconexas da realidade do aluno, entretanto devem estar sempre interrelacionadas aos conteúdos científicos (CHASSOT, 2003). Segundo as Diretrizes Curriculares do Paraná:

É necessário perceber que o experimento faz parte do contexto de sala de aula e que não se deve separar a teoria da prática. Isso porque faz parte do processo pedagógico que os alunos se relacionem com os fenômenos sobre os quais se referem os conceitos a serem formados e significados (PARANA, 2008, p. 20).

A atividade experimental é uma ferramenta necessária, mas não suficiente. Não basta que o professor desenvolva as atividades, mas que ele saiba empregá-las de modo a oferecer benefícios na compreensão dos fenômenos químicos estudados (MALDANER, 2003; CHASSOT, 2003). Além disso, as aulas práticas não necessitam de materiais sofisticados para sua execução e pode até mesmo ser desenvolvida em sala de aula. O importante é que seja desenvolvida por meio de uma metodologia de ensino que valorize a participação do estudante, de modo que sejam conduzidos a significar os conceitos, favorecendo a aquisição dos conhecimentos científicos e formação de cidadãos críticos e autônomos, que sejam capazes de tomar decisões e opinar de forma fundamentada em questões relacionadas a ciência, tecnologia, sociedade e ambiente.

No ensino de Química, os experimentos são importantes, mas eles não vão resolver o problema da aprendizagem. Considerando $o$ fato de que a aula experimental sem investigação, discussão, problematização e reflexão, tende a ser pior que uma aula expositiva, pois os alunos não conseguem encontrar significado nas mesmas (MALDANER, 2003). Então, dizer que aulas práticas são importantes no ensino de química, não implica na realização de experimentos em todas as aulas. $\mathrm{O}$ importante não é a quantidade, mas sim a seleção e utilização de aulas dentro de uma metodologia adequada de ensino, a qual favoreça a didática pedagógica do professor, beneficiando a aprendizagem.

O professor deve atuar como facilitador da aprendizagem apresentando os experimentos sob a forma de problema a ser resolvido, levando o aluno a problematização dos conteúdos e consequentemente a discussões, levantamento de hipótese, questionamentos e busca por resoluções. Desta forma, é importante partir do conhecimento empírico do aluno para facilitar o processo de aprendizagem dos conceitos químicos. Entretanto, ao final da atividade investigativa faz-se necessário que ocorra a superação das pre-concepções e que o aluno atinja um novo e superior estado de 
conhecimento por meio da apreensão dos conteúdos elaborados (BRUNER, 1998; AUSUBEL, 1995; MOREIRA, 1999). A aprendizagem realizada de forma hipotética permite que o aluno atinja um nível de compreensão do conteúdo que vai além da simples memorização, ou seja, ele consegue compreender as relações entre os fatos.

Por isso, o processo ensinoaprendizagem através das atividades investigativas torna-se importante, pois os alunos podem através da ação direta sob o objeto de estudo e efetiva interação com os colegas, com o professor e com o meio, relacionar os conceitos teóricos ministrados na disciplina de química ao seu cotidiano, revelando deste modo que conseguiram encontrar significado nos conteúdos científicos estudados.

Segundo Piaget (1997), o que motiva o ser humano ao aprendizado são os desafios, os problemas do cotidiano, os conflitos intelectuais. A medida que o indivíduo passa a interagir com o mundo ao seu redor, ele começa a atuar e a modificar ativamente a realidade que a envolve. Mas para que o sujeito possa atuar é necessário que possua um esquema, de modo a interpretar e organizar a ação para que possa ser colocada em prática.

A inteligência se desenvolve por meio de um intercâmbio permanente com o objeto, o que resulta em um constante processo de equilibração, visando a melhor adaptação do sujeito ao meio social a que está inserido. Sendo assim, ao encontrar uma situação nova, inicialmente instala-se uma situação de desequilíbrio. O indivíduo, então, procura novos esquemas ou formas para lidar com essa situação, o que envolve consequentemente uma crescente transformação de suas ações, para adaptarse e retornar a um novo estado de equilíbrio (PIAGET, 1997).

Seguindo as perspectivas construtivistas, o processo de aquisição do conhecimento deriva das múltiplas interações realizadas pelo sujeito com os objetos do meio no qual está inserido, sendo que o sujeito é sempre aquele que vai em busca do conhecimento e o objeto é sempre aquilo que se deseja conhecer. Nesse contexto, o conhecimento se dá através de múltiplas interações, as quais ocorrem a partir da ação do sujeito sobre o objeto de estudo (PIAGET 2004).

Acredita-se, por isso, que as atividades experimentais facilitam a aprendizagem dos conceitos, pois quando realizado dentro de uma proposta investigativa, coloca o aluno em contato direto com o objeto de estudo da química, via experimentação. Deste modo, podem estimular o raciocínio lógico e despertar inúmeras habilidades cognitivas, induzindoos à questionamentos, dúvidas, inquietações 
e busca por soluções satisfatórias aos problemas apresentados.

Corrobora-se com a ideia de que o aluno só adquire o conhecimento à medida que se posiciona de modo ativo diante do conteúdo, pois sem vontade nem iniciativa para desvendar um conhecimento não há aprendizagem (BESSA, 2008). Portanto, o papel do professor é fazer com que a criança e o jovem entrem em contato com os conteúdos de modo participativo, criativo, contextualizado e construtivo.

\section{CONSIDERAÇÕES FINAIS}

Atualmente pode-se notar que os currículos enfatizam o uso das atividades experimentais, isto devido às orientações advindas dos documentos PCNEM e Diretrizes Curriculares do Paraná, os quais apoiam o uso desta ferramenta quando a mesma está vinculada a uma metodologia de ensino adequada, focada na investigação, problematização e participação ativa do aluno no processo. Segundo esses documentos a experimentação apresenta importante função pedagógica, pois pode impulsionar e motivar os alunos a se interessarem mais pelas aulas de química.

Dessa forma, cabe ao professor a tarefa de preparar adequadamente as aulas experimentais, com o intuito de auxiliar os alunos a aprender por meio do estabelecimento de inter-relações entre teoria e prática, as quais estão inerentes ao processo do conhecimento escolar das ciências, dentre elas a química. Considerando o fato crucial de que a teoria e o experimento interagem e são dependentes entre si. Deste modo, o experimento resulta na elaboração da teoria, a qual estabelece a forma como devem ser realizados os experimentos (GALLIAZZI, 2001; MALDANER, 2003).

Então, infere-se que os laboratórios são locais onde os professores podem melhorar a qualidade de suas aulas, planejando e organizando o processo de ensino para uma melhor compreensão dos conhecimentos científicos, visando despertar no aluno a curiosidade e um maior interesse pela disciplina. Levando aos mesmos a oportunidade de compreenderem os fenômenos químicos através de experimentos adequados, os quais devem estar encharcados na realidade dos educandos, obtendo-se assim uma aprendizagem significativa.

\section{REFERÊNCIAS}

AUSUBEL, D. Psicologia educacional. Rio de Janeiro: Interamericana, 1995.

BESSA, V. H. Teorias da aprendizagem Curitiba: IESDE Brasil S.A., 2008.

BRASIL. Ministério da Educação. Parâmetros Curriculares Nacionais do Ensino Médio.. Brasília-DF: ME, 2006.

BRUNER, J. 0 processo da educação. São Paulo: Edições 70, 1998. 
CHASSOT, A. Para que(m) é útil o ensino?. 2. ed. Canoas: Ed. ULBRA, 2004

CHASSOT, A. A Educação no Ensino de Química. ljuí: Unijuí, 1990.

GALIAZZI, M. C. et al. P. Objetivos das atividades experimentais no ensino médio: a pesquisa coletiva como modo de formação de professores de ciências. Ciência \& Educação, v. 7, n. 2, 2001.

GIL PÉREZ, D.; VALDÉS CASTRO, P. La orientación de las prácticas de laboratorio como investigación: unun ejemplo ilustrativo. Enseñanza de lãs Ciencias, v. 14, n. 2, p. 155163, 1996.

LIBÂNEO, J. C. Pedagogia e Modernidade na educação: presente e futuro da escola. In: SEMINÁRIO NACIONAL DE INFÂNCIA, ESCOLA, MODERNIDADE. 1995. Anais... Curitiba: Universidade Federal do Paraná, 1995.

MALDANER, O. A. A formação inicial e continuada de professores de Química:

Professor/Pesquisador. 2.ed. Ijuí: Ed. Unijuí, 2003.

MOREIRA, M. Aprendizagem Significativa. Brasília: UNB, 1999.

LIMA, J. F. L. et al. A contextualização no ensino de química. Revista Química Nova na Escola, São Paulo, n. 11, 2000.

PIAGET, J. O nascimento da inteligência na criança. Rio de Janeiro: Zahar, 1997.

PIAGET, J. Linguagem e pensamento da criança. Rio de Janeiro: Fundo de Cultura, 1990.

PARANÁ. Secretaria de Estado da Educação. Diretrizes curriculares de Química para a Educação Básica. Curitiba, PR: Secretaria de Estado da Educação, 2008.
Recebido para publicação em 14/04/2014 Revisado em 01/12/2014

Aceito em 19/01/2015 